\title{
SYNTHESIS AND CHARACTERIZATION OF BIOBASED EPOXIDIZED EDIBLE OILS
}

\author{
NUR SHAFIQA SAYUTI, RADIAH ALI AND SABIQAH TUAN ANUAR*
}

Faculty of Science and Marine Environment, Universiti Malaysia Terengganu, 21030 Kuala Nerus, Terengganu, Malaysia.

*Corresponding author: sabiqahanuar@umt.edu.my

http://doi.org/10.46754/umtjur.2021.10.020

\begin{abstract}
Nowadays, major pollutions present in the environment are produced by non-degradable substances. Eventually, the use of non-degradable products will increase carbon footprint in the atmosphere. In this study, modifications of five vegetable oils into biobased epoxides are reported. The oils used in this study were commercial palm oil, rice bran oil, canola oil, soybean oil and sunflower oil. The vegetable oils were refluxed using formic acid and hydrogen peroxide at temperature ranges of 45 to $50^{\circ} \mathrm{C}$ and 60 to $65^{\circ} \mathrm{C}$ for seven hours in order to change the chemical structure of carboncarbon double bonds into oxirane rings. The mixture was then processed by liquid-liquid extraction to separate epoxide oil from liquid that was present during the reflux process. The obtained oils were then analyzed using ATR-FTIR and the presence of oxirane rings were observed at the wavelength $v=1080.79 \mathrm{~cm}^{-1}$ and $836.10 \mathrm{~cm}^{-1}$ for epoxidized palm oil, $v=1107.14 \mathrm{~cm}^{-1}$ and $841.11 \mathrm{~cm}^{-1}$ for epoxidized rice bran oil, $v=1050.13 \mathrm{~cm}^{-1}$ and $850.35 \mathrm{~cm}^{-1}$ for epoxidized canola oil, $v=1083.99$ $\mathrm{cm}^{-1}$ and $825.03 \mathrm{~cm}^{-1}$ for epoxidized soybean oil and $v=1095.57 \mathrm{~cm}^{-1}$ and $820.16 \mathrm{~cm}^{-1}$ for epoxidized sunflower oil, respectively. Additionally, an absorption band at $v=1462 \mathrm{~cm}^{-1}$ was observed in all oil samples, indicating the presence of $\mathrm{C}-\mathrm{C}$ oxirane. In future, these epoxidized oils can serve as a great potential as new starting materials for the synthesis of lipid biopolymers.
\end{abstract}

Keywords: Biomaterials, epoxidized palm oil, epoxidized rbo, vegetable oils, ATR-FTIR.

\section{Introduction}

Vegetable oils are predominantly with fatty acids esterified to triacylglycerides (TAG), which mainly consist of unsaturated C16-C22 fatty acids (Fomitšov, 2019). Vegetable oils, especially palm olein, is widely used in Malaysia as edible oil for cooking and contain high saturated fat with low trans fats (Imosis et al., 2015). Figure 1 shows the general triglyceride structure of common vegetable oil containing unsaturated bonds.

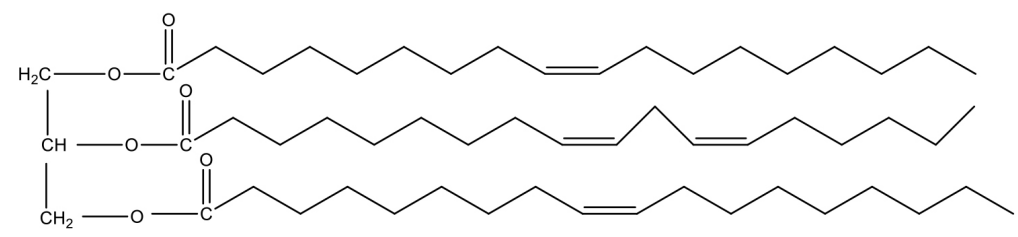

Figure 1: Chemical structure of lipid of vegetable oil

Vegetable oils can be extracted from the seeds and the fruits of the plants. Soybean oil and sunflower oil are the examples of oil that are extracted from the seeds while palm oil, olive oil and rice bran oil are the examples of oil extracted from the fruit of the plant (Bulley et al., 1984). Vegetable oil is widely used to substitute fossil fuel as feedstock because of its stable chemical and physical properties (Fomitšov, 2019; Kouzu \& Hidaka, 2012; Nyashina \& Strizhak, 2019). Vegetable oil is a renewable source with great properties such as high flash point, high lubricity, biodegradable and non-toxic (Borugadda et al., 2017). The physical properties of vegetable oils show that they can be used to synthesize a new biomaterial as they are safe to the environment. 
Table 1 shows typical fatty acid compositions in the edible vegetable oils as expressed by percentage weight of fatty acid methyl ester by gas chromatography analysis.

Table 1: Fatty acid composition in selected edible oils

\begin{tabular}{|c|c|c|c|c|c|}
\hline FAs (\%) & Palm Oil $^{1}$ & Rice Bran Oil ${ }^{2}$ & Canola Oil $^{3}$ & Soybean Oil $^{4}$ & Sunflower Oil \\
\hline C12:0 & 0.2 & nd & nd & nd & 0.02 \\
\hline C14:0 & 1.1 & 0.39 & nd & nd & 0.09 \\
\hline C16:0 & 44.0 & 20.0 & 4.3 & 11.5 & 6.2 \\
\hline C16:1 & nd & 0.19 & 0.2 & nd & 0.12 \\
\hline $\mathrm{C} 17: 0$ & nd & nd & nd & nd & 0.02 \\
\hline C18:0 & 4.5 & 2.1 & 1.8 & 3.62 & 2.8 \\
\hline C18:1 & 39.2 & 42.7 & 62.3 & 24.0 & 28.0 \\
\hline C18:2 & 10.1 & 33.1 & 19.4 & 54.6 & 62.2 \\
\hline C18:3 & 0.4 & 0.45 & 9.2 & 5.87 & 0.16 \\
\hline C20:0 & 0.1 & nd & 0.60 & 0.46 & 0.21 \\
\hline C20:1 & nd & 1.11 & 1.20 & $\mathrm{Nd}$ & 0.18 \\
\hline $\mathrm{C} 22: 0$ & nd & nd & nd & $\mathrm{Nd}$ & nd \\
\hline
\end{tabular}

nd, not detected; ${ }^{1}$ Mancini et al. (2015); ${ }^{2}$ Orsanova et al. (2015); ${ }^{3}$ Ghazani et al. (2014); ${ }^{4}$ Sahoo et al. (2015)

From Table 1, the compositions of fatty acids in each oil are varied according to saturation and unsaturation moieties of the fatty chains. As such, palm olein consists of $49.9 \%$ saturated fatty acids (SFAs), followed by $39.2 \%$ monounsaturated fatty acids (MUFAs) and only $10.5 \%$ polyunsaturated fatty acids (PUFAs). Meanwhile, rice bran oil contains higher number of MUFAs (44.0\%) together with PUFAs $(33.5 \%)$ and almost $22.5 \%$ of SFAs. The MUFAs are the most abundant fatty acids in canola oil, amounting to $63.7 \%$, followed by $26.6 \%$ PUFAs and only $6.7 \%$ SFAs. The fatty acid compositions of soybean and sunflower oils somewhat fall in the range of 9.34-15.58\% of SFAs, MUFAs $24.0 \%-28.3 \%$ and $60.47 \%$ $62.36 \%$ PUFAs.

Due to their versatility and structure, vegetable oils can be modified by few chemical reactions into other products such as esterification, epoxidation, hydrolysis, saponification and transesterification reactions, whereas the epoxidation process will produce epoxidized oils. This reaction involves the addition of single oxygen atom into either monounsaturated or polyunsaturated carboncarbon double bonds in the fatty acid chains by percarboxlic acids or organic/inorganic peroxides as oxidizing agent (Omonov et al., 2016). This will eventually change the original chemical structure into epoxide, or also known as oxirane or epoxy group, with a structure of cyclic with three membered ring structures. Epoxide has highly strained ring structure which makes the epoxy group more reactive than other ethers. This makes epoxy group important as intermediates for a variety of products (Arniza et al., 2015; Goud et al., 2006).

During the epoxidation process, the high content of unsaturated carbon-carbon double bond is more desirable. Thus, the fatty acid constituent of vegetable oils can be used to assume the content of the epoxy group formed (Pérez et al., 2009). The epoxy group that forms in the vegetable oil can be monitored directly with oxirane oxygen content analysis and also by iodine value analysis for indirectly monitoring (Parreira et al., 2002). The purpose of this paper 
is mainly to show how vegetable oils could be modified by simple epoxidation reaction to further serve as renewable material feedstock. While fatty acid profiles of commodities such as sunflower, soy bean and canola oils are major lipid of interest in the world (Starostina et al., 2020), local commodity in Malaysia such as palm oil was also given consideration in this study.

\section{Materials and Methods}

\section{Chemicals and Materials}

The starting oils of palm olein, rice bran oil, canola oil, soybean oil and sunflower oil were all purchased from the local supermarket. Additionally, chemicals and reagents such as formic acid (reagent grade 95\%), hydrogen peroxide, sodium chloride, sodium hydroxide and n-hexane were attained from Sigma-Aldrich (Malaysia).

\section{Epoxidation Reaction of Edible Oils}

The epoxidation of edible oils was carried out according to the previous report by Omanov et al. (2016) with slight modifications. Each of the edible vegetable oil (25 g) was weighed using analytical weighing balance. The epoxidation was carried out by adding $23 \mathrm{~g}$ of formic acid (reagent grade 95\%) and $102 \mathrm{~g}$ of $30 \%$ hydrogen peroxide to each of the starting oil with the ratio of 1:1:6 (edible oil: formic acid: hydrogen peroxide, w/w). In brief, formic acid and vegetable oil were mixed together in a 100 $\mathrm{mL}$ beaker and the mixture solution was then poured into the three neck flaks of a reflux system. Hydrogen peroxide was added drop wise to the solution mixture, and this process was completed in one hour with the temperature of the mixture maintained at $\left(45\right.$ to $\left.50^{\circ} \mathrm{C}\right)$. The mixture was stirred continuously at $10 \mathrm{rpm}$ speed to ensure its homogeneity. The reaction was monitored closely since the exothermic reaction has occurred due to reactive reaction between formic acid and hydrogen peroxide. The reaction temperature was then increased to 60 to $65^{\circ} \mathrm{C}$ for another 6 hours. After 6 hours, the epoxidized oil was cooled at room temperature before continuing with the next process. All of the processes were carried out in the fume hood.

\section{Liquid-Liquid Extraction of Epoxidized Oils}

Liquid - liquid extraction (LLE) is a method to separate two immiscible solutions, in which solvent polarity index was used to identify the suitable solvent to separate between two immiscible layers. Approximately, 10 $\mathrm{g}$ of epoxidized oil samples was weighed. Meanwhile, $5 \mathrm{~g}$ of sodium hydroxide $(\mathrm{NaOH})$ and sodium chloride $(\mathrm{NaCl})$ were separately weighed and then diluted with distilled water up to the scale of the volumetric flaks $(100 \mathrm{~mL})$. The oil samples were poured into the separating funnel followed by $15 \mathrm{~mL}$ of $\mathrm{NaOH}$ solution, 15 $\mathrm{mL}$ of $\mathrm{NaCl}$ solution and $15 \mathrm{~mL}$ of $\mathrm{n}$-hexane. The schematic Figure 2 shows the layers of the mixture due to the differences in density and polarity of the solutions and samples. The function of $\mathrm{NaOH}$ in this study was to neutralize formic acid (strong acid) that might be residually present in the oil samples. While, the function of $\mathrm{NaCl}$ was to absorb the left-over moisture that is in the oil samples (Mungroo et al., 2008). Besides, the function of n-hexane was to break the emulsion between formic acid and hydrogen peroxide that still remained in the epoxidized oil samples. 


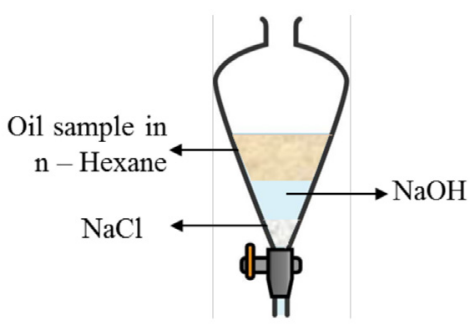

Figure 2: The layer of the epoxidized oil in LLE solvent mixtures

Chemical Characterization Using Attenuated Total Reflectance Fourier Transform Infrared Spectroscopy

In this study, the chemical analysis for the vegetable oils as starting material (not shown in the results) and epoxidized oils were carried out using a Shimadzu Fourier Transform Infrared spectroscopy with Attenuated Total Reflectance mode (ATR-FTIR, Shimazdu, Japan) in the mid-infrared wavelength of $4000-400 \mathrm{~cm}^{-1}$. In brief, $10 \mu \mathrm{L}$ of oil samples was dropped onto the ATR diamond accessory and each sample was analyzed with $4 \mathrm{~cm}^{-1}$ resolution and at 40 scans each. The spectrum obtained from the analysis underwent manipulation process such as baseline correction, normalization, smoothing and peak assignation in order to increase the image resolution and visual properties.

\section{Results and Discussion}

A complete modification of palm olein, rice bran oil, canola oil, soybean oil and sunflower oil with the presence of reagents $\left(\mathrm{CH}_{2} \mathrm{O}_{2}\right.$ and $\left.\mathrm{H}_{2} \mathrm{O}_{2}\right)$ has produced epoxidized oils. The formation of epoxy group occurred when the solvent reacted with carbon-carbon double bond in the chemical structure (Chandrasekara et al., 2011). Figure 3 shows the mechanism example of the conversion of palm olein into epoxidized palm oil.

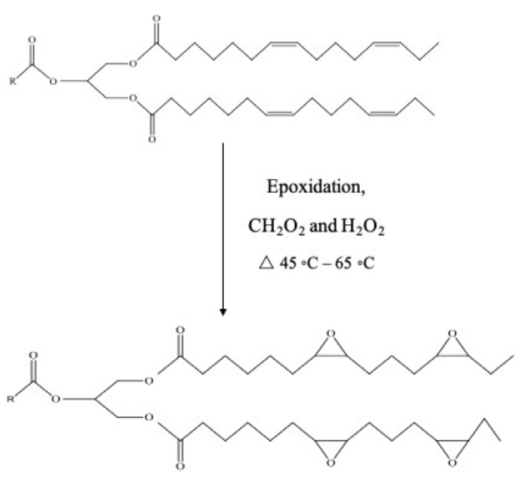

Figure 3: Mechanism of the synthesis of epoxidized palm oil

The oxirane ring in the structure was formed by the addition of nucleophile that was present in the $\mathrm{CH}_{2} \mathrm{O}_{2}$ and the homogenous acid catalyst $\mathrm{H}_{2} \mathrm{O}_{2}$ (Centi et al., 2000; Nor et al., 2017). In the reaction, the nucleophilic addition was more favorable due to the number of carbon-carbon double bond and no other reaction occurred during the process. In this study, the physical characteristic that can be observed by naked eyes was the texture of the oil, as illustrated in Figure 4. 


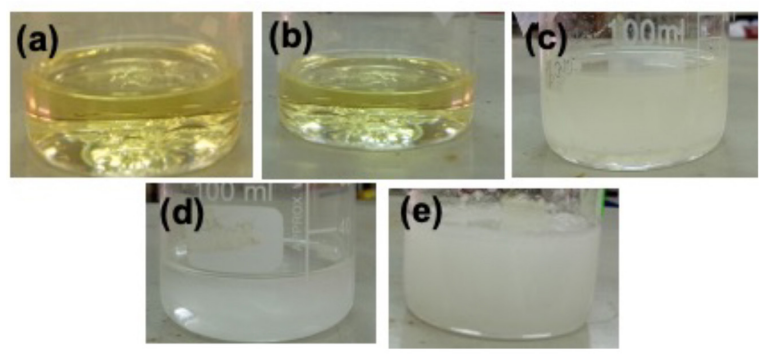

Figure 4: Variation of textures of epoxidized oil samples: (a) palm oil, (b) rice bran oil, (c) canola oil, (d) soybean oil and (e) sunflower oil

Initially, the texture of each starting oil form was in the same liquid state and yellowish in color, however after the modification, the canola oil, soybean oil and sunflower oil visually became clearer and lighter in colour. These changes were in agreement with the previous findings by Sienkiewicz and Czub (2016) where they found that the epoxidation of soybean process oil resulted in a formation of clearer and yellowish liquid oil, regardless of the reaction conditions. The colour changes were mainly due to the SFAs fatty acid composition in oils, where the percentage of SFAs in these three respective oils is lower than others (Table 1).

FTIR spectra indicated the functional groups that were presented in the chemical structure. This technique detects the vibration of a molecule in the compound, thus providing the various types of bonds that exist (Boyatzis et al., 2016). In this work, each of the oils showed discrepancies in peak range of oxirane ring functionality due to the variation of numbers of unsaturated carbon-carbon double bond that was present in the oil structure. Moreover, the intensity of the peaks (strong, medium, and weak) showed whether the formation of oxirane ring was abundant or not. Table 2 shows the assignment for most characteristic Infrared band of palm olein, rice bran oil, canola oil soybean oil and sunflower oil that was previously reported (Hashim et al., 2017; Irnawati et al., 2020; Purbaya et al., 2015; Setyaningrum et al., 2013; Shi et al., 2017).

Table 2: ATR-FTIR absorption characteristics of vegetable oils based on reference studies

\begin{tabular}{lccccc}
\hline \multirow{2}{*}{ Functional Group } & \multicolumn{5}{c}{ Wavenumber (cm $^{-1}$ ) } \\
\cline { 2 - 6 } & Palm Oil $^{\mathbf{1}}$ & Rice Bran Oil $^{\mathbf{2}}$ & Canola Oil $^{\mathbf{3}}$ & Soybean Oil $^{\mathbf{4}}$ & Sunflower Oil $^{\mathbf{5}}$ \\
\hline C-H str (next to C=C) cis & 3008 & 3007 & 3008 & 3005 & 3008 \\
C-H asymmetry str & 2953,2922 & 2953,2922 & 2958,2925 & 2953,2922 & 2925 \\
C-H symmetry str & 2853 & 2853 & 2854 & 2852 & 2854 \\
C=O str & 1744 & 1743 & 1747 & 1746 & 1746 \\
C-C str & & & & & n.m \\
C-C str & n.m & 1654 & n.m & 1654 & 1235 \\
C-O str & 1160 & $1159-1096$ & n.m & 1160 & 1163 \\
C-H ${ }_{3}, \mathrm{CH}_{2}$ bend & 1461 & 1460,1378 & 1465,1376 & 1463,1377 & 1464,1377 \\
\hline
\end{tabular}

n.m: not mentioned; ${ }^{1}$ Hashim et al. (2017); ${ }^{2}$ Irnawati et al. (2020); ${ }^{3}$ Shi et al. (2017); ${ }^{4}$ Setyaningrum et al. (2013); ${ }^{5}$ Purbaya et al. (2015) 
The data showed a typical characteristic of absorption peaks for common triglycerides in edible oils. Based on the previous studies, absorption bands at $\mathrm{n}=3008-3005 \mathrm{~cm}^{-1}$ are notable for the stretching vibration for the cis double bonds of unsaturated fatty acids. However, in the present study, this unsaturated C-H stretching peak of hydrocarbon chain would later disappear from the spectra of epoxidized oils (see Table 3), with the exception for the epoxidized soybean oil. This indicated that the unsaturated fatty acid moieties of the edible oils have turned into epoxide. Additionally, in pure unmodified oils, strong band absorptions were usually observed in the region of $n=2953$ $-2852 \mathrm{~cm}^{-1}$ which were attributed to $\mathrm{C}-\mathrm{H}$ asymmetry stretching vibrations. The bending vibrations of methyl $\left(\mathrm{CH}_{3}\right)$ and methylene $\left(\mathrm{CH}_{2}\right)$ groups are also reported in the range of $n=1465$ $-1460 \mathrm{~cm}^{-1}$ and $\mathrm{n}=1378-1376 \mathrm{~cm}^{-1}$. Previous studies also reported the appearance of large peak at $\mathrm{n}=1747-1743 \mathrm{~cm}^{-1}$ which corresponded to $\mathrm{C}=\mathrm{O}$ double bond stretching vibration in triglyceride of all selected oils, together with stretching vibration peak of $\mathrm{C}-\mathrm{O}$ in the region of $\mathrm{n}=1163-1096 \mathrm{~cm}^{-1}$ (Hashim et al., 2017; Irnawati et al., 2020; Purbaya et al., 2015; Setyaningrum et al., 2013; Shi et al., 2017).

The ATR-FTIR absorption characteristics for palm olein, rice bran oil, canola oil soybean oil and sunflower oil are shown in Figures 5 to 9. In the FTIR spectrum of epoxidized palm olein (Figure 5), the weak intensity of $\mathrm{CH}_{2}-\mathrm{O}$ $\mathrm{CH}$ stretching was present at $\mathrm{n}=1250 \mathrm{~cm}^{-1}$ and bending at $n=1098 \mathrm{~cm}^{-1}$, together with oxirane peaks at range of $\mathrm{n}=1462 \mathrm{~cm}^{-1}$ and $900-800$ $\mathrm{cm}^{-1}$. This intensity indicated that the quantity of oxirane ring present in the chemical structure was low. This spectrum was compared to epoxide palm oil acrylate from other analysis of Salih et al. (2015). The comparison between these two epoxide oils proved that formation of epoxide from palm oil product with the presence of $\mathrm{C}-\mathrm{O}-\mathrm{C}$ functional group at the fingerprint region.

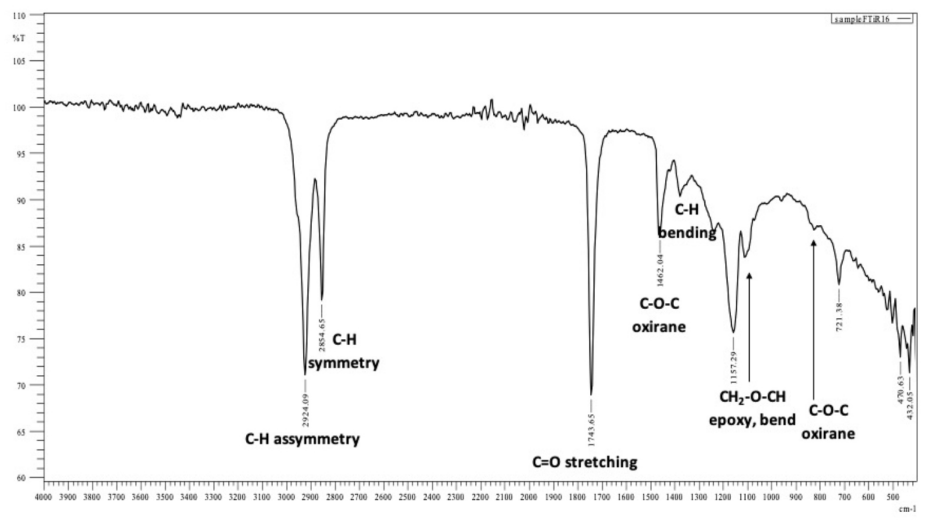

Figure 5: ATR-FTIR spectrum of epoxidized palm oil

Previously, Tavassoli-Kafrani et al. (2017) successfully used ATR-FTIR method to determine the oxirane oxygen content (OOC) produced in the epoxidation process of vegetable oils by measuring the changes in epoxy functional group absorption in the range of $\mathrm{n}=1497-1432 \mathrm{~cm}^{-1}$. In this current work, peaks at $721.38 \mathrm{~cm}^{-1}$ and $820 \mathrm{~cm}^{-1}$, albeit low intensity, were attributed to the presence of the
$\mathrm{C}-\mathrm{O}-\mathrm{C}$ oxirane, and in agreement with previous findings reported by Vlcek and Patrovic (2006). Additionally, the methyl group $\left(\mathrm{CH}_{3}\right)$ in the chemical structure showed strong intensity at $\mathrm{n}=2924.09 \mathrm{~cm}^{-1} \quad \mathrm{C}-\mathrm{H}$ asymmetry stretching, while methylene $\left(\mathrm{CH}_{2}\right)$ showed strong intensity at $\mathrm{n}=2854.65 \mathrm{~cm}^{-1} \mathrm{C}-\mathrm{H}$ symmetry stretching, and the $\mathrm{C}-\mathrm{H}$ in deformation in the figure at $\mathrm{n}=1377 \mathrm{~cm}^{-1}$, all showing the back bone of fatty 
acid chain of epoxide products. The fatty acid structure in palm oil with a balance of saturated and unsaturated constituents hence contributed to the lower oxirane formation, in comparison to other types of oils (Chandrasekara et al., 2011; Salih et al., 2015).

The functional groups for epoxidized rice bran and canola oils were shown in FTIR spectra in Figures 6 and 7 and tabulated in Table 3. In FTIR spectrum, the C-O-C epoxy functionality was attributed to the peaks at $\mathrm{n}=1462 \mathrm{~cm}^{-1}, 820 \mathrm{~cm}^{-1}$ and $721 \mathrm{~cm}^{-1}$, which indicated the formation of oxirane groups in both oils. Similarly, additional peaks of $\mathrm{CH}_{2}-$ $\mathrm{O}-\mathrm{CH}$ stretching and bending were present in the C-O region of $\mathrm{n}=1247 \mathrm{~cm}^{-1}$ and $1107 \mathrm{~cm}^{-1}$, similar to the recent findings reported by Tran et al. (2020) and Nicolic et al. (2010). On the other hand, the methyl group $\left(\mathrm{CH}_{3}\right)$ showed strong intensity at $\sim \mathrm{n}=2924 \mathrm{~cm}^{-1}, \mathrm{CH}_{2}$ at $\mathrm{n}=2854 \mathrm{~cm}^{-1}$ and $\mathrm{C}-\mathrm{H}$ bending at $\mathrm{n}=1377 \mathrm{~cm}^{-1}$.

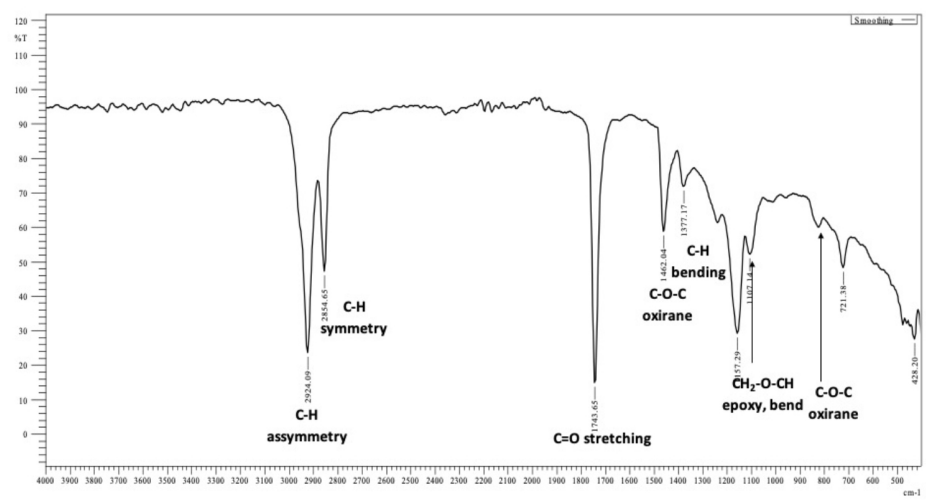

Figure 6: ATR-FTIR spectrum of epoxidized rice bran oil

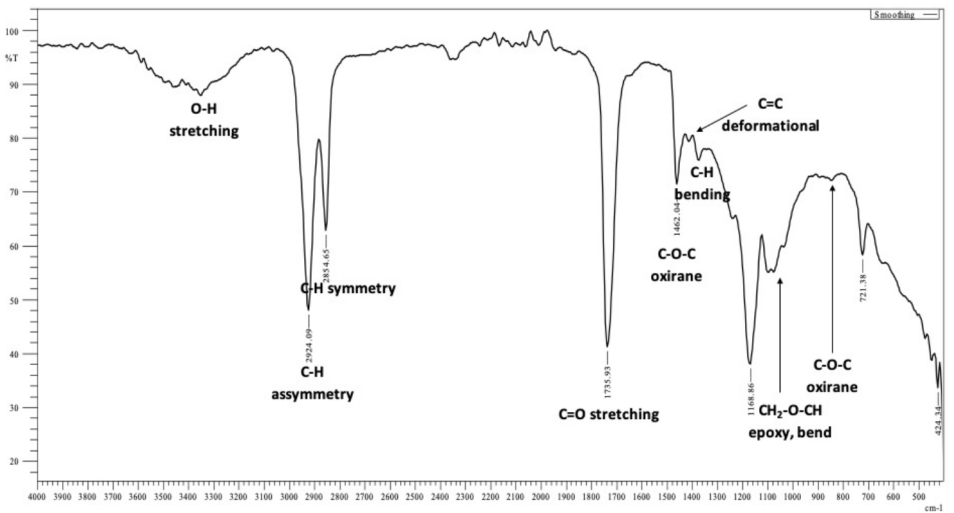

Figure 7: ATR-FTIR spectrum of epoxidized canola oil

The difference between epoxidized palm oil and rice bran oil with canola oil is that the canola oil reaction products showed another reading in the range of $\mathrm{n}=1420 \mathrm{~cm}^{-1}$, possibly from $-\mathrm{C}=\mathrm{CH}$ deformational, a characteristic peak for unsaturated bond, and comparative to the same peak reported by Sienkiewicz and Czub (2016) at $\mathrm{n}=1418 \mathrm{~cm}^{-1}$. This suggested that the oils contained unmodified double bonds, but relatively in small amounts since the intensity of the peak was small. In the FTIR spectrum of epoxidized canola oil, the formation of $\mathrm{O}-\mathrm{H}$ 
stretching at $\mathrm{n}=3360 \mathrm{~cm}^{-1}$, possibly indicated the presence of moisture in the sample. Both rice bran and canola oils can undergo a variety of processes that can change their chemical structure into epoxide. The common process that has being used is transforming unsaturated carbon double bond into oxirane ring, by breaking the bond by adding performic acid as the main oxidizing agent (Borugadda et al., 2017). These oils have lower polyunsaturated carbon double bond compared to soybean oil and sunflower oil, and also have high monounsaturated carbon double bond. Due to this, the oils have a high ability to change the chemical structure into epoxy group effectively (Adebiyi et al., 2008; Przybylski, 2005).
Figures 8 and 9 represent the ATR-FTIR spectra of soybean oil and sunflower oil after epoxidation reaction. Both spectra show the presence of vibrational band at $n=3400-3300$ $\mathrm{cm}^{-1}$ for O-H stretching with weak intensity, was attributed to the presence of moisture in the oil samples. The C-O-C oxirane functional group for epoxide functionality were consistently shown at $\mathrm{n}=1462 \mathrm{~cm}^{-1}$ with strong intensity and $\mathrm{n}=820 \mathrm{~cm}^{-1}$ at weak intensity. Additionally, the presence of strong absorption at $\mathrm{n}=1095 \mathrm{~cm}^{-1}$ was attributed to the presence of $\mathrm{CH}_{2}-\mathrm{O}-\mathrm{CH}$ epoxy bending, somewhat similar to the report by Nikolic et al. (2010), although this peak was slightly shifted to the left in this work. This indicated that there was a high amount of oxirane ring form in both oils.

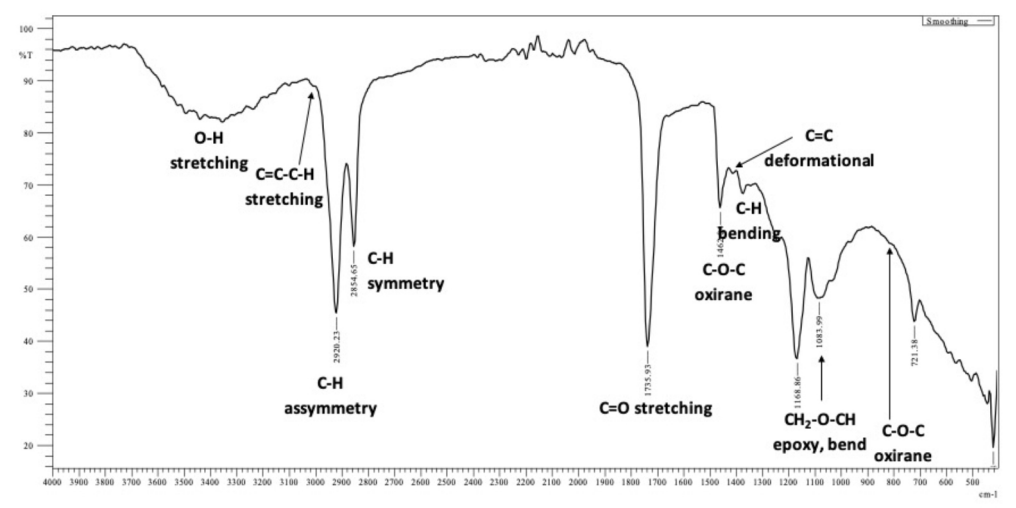

Figure 8: ATR-FTIR spectrum of epoxidized soybean oil

However, the presence of $-\mathrm{C}=\mathrm{CH}$ deformational characteristic peaks $(\sim \mathrm{n}=1420$ $\mathrm{cm}^{-1}$ ) in both oil samples and additional band attributed to the $\mathrm{C}-\mathrm{H}$ stretching next to carboncarbon double bond, $-\mathrm{C}=\mathrm{C}-\mathrm{H}\left(\mathrm{n}=3010 \mathrm{~cm}^{-1}\right)$ in epoxidized soybean oil also suggested the oils still contained the unmodified double bonds. Previously, the presence of low intensity peak at the range of $\mathrm{n}=3017-3004 \mathrm{~cm}^{-1}$ was used to measure the relative changes in iodine value (represent carbon-carbon double bond) of unreacted edible oils (Tavassoli-Kafrani et al., 2017). Basically, the process in changing the chemical structure of these types of oils into epoxy functional group is the same for the other vegetable oils. However, since their TAG oil structures have relatively high PUFAs carbon double bonds (>60\%), refer to Table 1) as compared to monounsaturated carbon double bonds, these oils have low ability to change all the unsaturated carbon double bond into epoxy group (Adebiyi et al., 2008; Adhvaryu \& Erhan, 2002). 


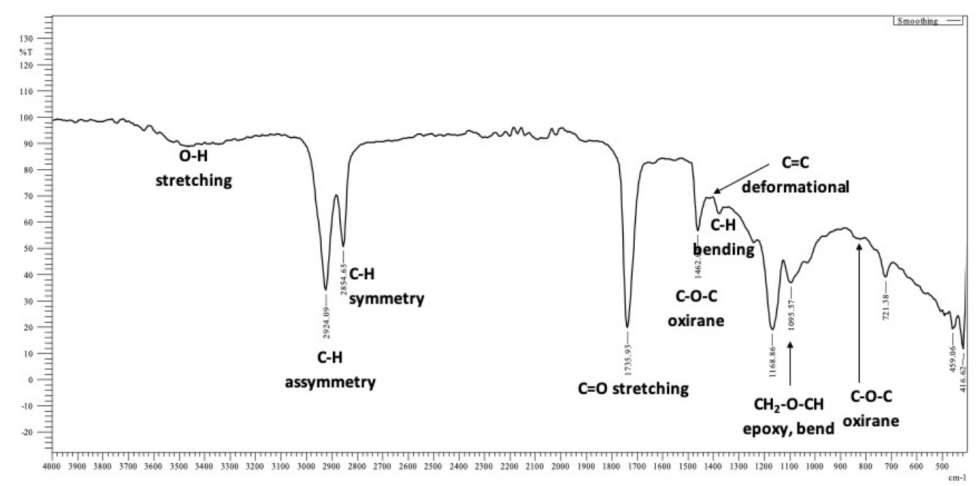

Figure 9: ATR-FTIR spectrum of epoxidized sunflower oil

Table 3 tabulates the FTIR peaks assignation that were present in the ATR-FTIR spectra in Figures 5 to 9 . It is worth noting that in order to ensure all the edible oils turn into epoxidized oils, the reaction process must be consistent and precise. These included the weight of the oil taken, ratio of oil and solvent, temperature used, volume of solvent and chemical analysis. The process should be consistent and precise to significantly archive high formation of oxirane ring (Mungroo et al., 2011).

Table 3: Respective ATR-FTIR absorption bands of the epoxidized edible oils

\begin{tabular}{lccccc}
\hline \multirow{2}{*}{ Functional Group } & \multicolumn{5}{c}{ Wavelength Peak $\left.\mathbf{( c m}^{-1}\right)$} \\
\cline { 2 - 6 } & $\begin{array}{c}\text { Epoxidized } \\
\text { Palm Oil }\end{array}$ & $\begin{array}{c}\text { Epoxidized } \\
\text { Rice Bran Oil }\end{array}$ & $\begin{array}{c}\text { Epoxidized } \\
\text { Canola Oil }\end{array}$ & $\begin{array}{c}\text { Epoxidized } \\
\text { Soybean Oil }\end{array}$ & $\begin{array}{c}\text { Epoxidized } \\
\text { Sunflower Oil }\end{array}$ \\
\hline O-H str & - & - & 3360 & 3300 & 3400 \\
C-H str (next to & - & - & - & 3010.25 & - \\
C=C) cis & & & & 2920.65 & 2924.09 \\
C-H asymmetry str & 2924.09 & 2924.09 & 2924.09 & 2854.65 & 2854.65 \\
C-H symmetry str & 2854.65 & 2854.65 & 2854.65 & 1735.98 & 1735.93 \\
C=O str & 1743.65 & 1743.65 & 1735.93 & 1462.04 & 1462.04 \\
C-C oxirane & 1462.04 & 1462.04 & 1462.04 & 825.03 & 820.16 \\
C-O-C oxirane & 836.10 & 841.11 & 850.35 & 1377.14 & 1377.12 \\
C-H bend & 1377.10 & 1377.17 & 1377.14 & 1083.99 & 1095.57 \\
CH - O-CH epoxy, & 1080.79 & 1107.14 & 1050.13 & & 1420.86 \\
bend & & - & 1420.86 & 1420.86 & \\
C=C deformation & - & & &
\end{tabular}

\section{Conclusion}

In conclusion, edible oils could have great potential as starting materials in the future synthesis of biobased epoxy products, owing to their high availability, versatility and fatty acid compositions. Modification process such as epoxidation under mild reaction condition will produce biobased feedstock with great properties such as low toxicity and desirable oxidative stability. During the epoxidation process of five different edible oils with 
different fatty acid constituents, it revealed that the starting oils with high unsaturated double bond content are more preferable because of higher ability for oil transformation into epoxide. Additionally, ATR-FTIR technique can be used as a rapid measurement and simple screening for the determination of epoxidation process of oil. However, this method can be further optimized for quantitative measurement such as in the calculation of percentage functional group conversion for the oxirane oxygen content. Additionally, other advanced chromatography techniques such as HPLCMS and H-NMR spectroscopy should also be considered as characterization methods. The obtained epoxidized oils can be further used in the ring opening reactions and polymerization for new biobased materials.

\section{Acknowledgements}

The authors gratefully acknowledge the financial support and research facilities from Universiti Malaysia Terengganu and the Faculty of Science and Marine Environment. The authors also would like to thank the Analytical Chemistry Laboratory science officer and technicians for the technical support given to the undergraduate student in completing this research.

\section{References}

Adebiyi, A. P., Adebiyi, A. O., Jin, D. H., Ogawa, T., \& Muramoto, K. (2008). Rice bran protein-based edible films. International Journal of Food Science and Technology, 43, 476-483.

Adhvaryu, A., \& Erhan, S. Z. (2002). Epoxidized soybean oil as a potential source of high temperature lubricants. Industrial Crops and Products, 247-254.

Arniza, M. Z., Hoong, S. S., Idris, Z., Yeong S. K., Hassan, H. A., Din, A. K., \& Choo, Y. M. (2015). Synthesis of transesterified palm olein-based polyol and rigid polyurethanes from this polyol. Journal of the American Oil Chemists'Society, 92, 243-255.
Borugadda, V. B., Somidi, A. K. R., \& Dalai, A. K. (2017). Chemical/structural modification of canola oil and canola biodiesel: Kinetic studies and biodegradability of the alkoxides. Lubricants, 5(2), 11.

Boyatzis, S. C., Velivasaki, G., \& Malea, E. (2016). A study of the deterioration of aged parchment marked with laboratory iron gall inks using FTIR-ATR spectroscopy and micro hot table. Heritage Science, 4(1), 13.

Bulley, N. R., Fattori, M., Meisen, A., \& Moyls, L. (1984). Supercritical fluid extraction of vegetable oil seeds. Journal of the American Oil Chemists'Society, 61, 1362-1365.

Centi, G., Perathoner, S., Torre, T., \& Verduna, M. G. (2000). Catalytic wet oxidation with $\mathrm{H}_{2} \mathrm{O}_{2}$ of carboxylic acids on homogeneous and heterogeneous Fenton-type catalysts. Catalysis Today, 55, 61-69.

Chandrasekara, G., Mahanama, M. K., Edirisinghe, D. G., \& Karunanayake L. (2011). Epoxidized vegetable oils as processing aids and activators in carbonblack filled natural rubber compounds. Journal of the National Science Foundation of Sri Lanka, 39(3), 243-250.

Fomitšov, M. (2019). Low-temperature supercritical conversion of Kukersite oil shale. Oil Shale, 36, 171-178.

Ghazani, S. M., Garcia-Llatas, G., \& Marangoni A. G. (2014). Micronutrient content of coldpressed, hot-pressed, solvent extracted and RBD canola oil: Implications for nutrition and quality. European Journal of Lipid Science and Technology, 116(4).

Goud, V. V., Patwardhan, A. V., \& Pradhan, N. C. (2006). Studies on the epoxidation of mahua oil (Modhumica indica) by hydrogen peroxide. Bioresource Technology, 97(12), 1365-1371.

Hashim, Z., Zaki, S. S. A. M., \& Muhamad, I. I. (2017). Quality Assessment of Fried Palm Oils using Fourier Transform Infrared Spectroscopy and Multivariate Approach. Chemical Engineering Transactions, 56, 829-834. 
Imosis, O. B., Ilori, G. E., Agho, I., \& Ekhator, J. O. (2015). Palm oil, its nutritional and health implications. Journal of Applied Sciences and Environmental Management, 19(1), 127-133.

Irnawati, Ryanto, S., Martono, S., \& Rohman, A. (2020). Determination of sesame oil, rice bran oil and pumpkin seed oil in ternary mixtures using FTIR spectroscopy and multivariate calibrations. Food Research, 4(1), 135-142.

Kouzu, M., \& Hidaka, J. S. (2011). Transesterification of vegetable oil into biodiesel catalyzed by $\mathrm{CaO}$ : A review. Fuel, 93, 1-12.

Mancini, A., Imperlini, E., Nigro, E., Montagnese, C., Daniele, A., Orrú S., \& Buono, P. (2015). Biological and nutritional properties of palm oil and palmitic acid: Effects on health. Molecules, 20(9), 1733917361 .

Mungroo, R., Goud, V. V., Pradhan, N. C., \& Dalai, A. K. (2011). Modification of epoxidised canola oil. Asia-Pacific Journal of Chemical Engineering, 6(1), 14-22.

Mungroo, R., Pradhan, N. C., Goud, V. V., \& Dalai, A. K. (2008). Epoxidation of canola oil with hydrogen peroxide catalyzed by acidic ion exchange resin. Journal of the American Oil Chemists' Society, 85, 887896.

Nor, N. M., Derawi, D., \& Salimon, J. (2017). Chemical modification of epoxidized palm oil for biolubricant application. Malaysian Journal of Analytical Sciences, 21, 14231431.

Nikolic, G., Zlatkovic, S., Cakic, M., Cakic, S., Lacnjevac, C., \& Rajic, Z. (2010). Fast Fourier Transform IR characterization of epoxy GY systems crosslinked with aliphatic and cycloaliphatic EH polyamine adducts. Sensors, 10, 684-696.

Nyashina, G., \& Strizhak, P. (2019). Experimental research of the effect of vegetable oil addition on the emissions during combustion of coal liquid fuels. Thermal Science, 23, 1237-1249.

Omonov, T. S., Kharraz, E., \& Curtis, J. M. (2016). The epoxidation of canola oil and its derivatives. RSC Advances, 6, 92874 92886.

Orsanova, J., Misurcova, L., Ambrozova J. V., Vicha R., \& Mlcek J. (2015). Fatty acids composition of vegetable oils and its contribution to dietary energy intake and dependence of cardiovascular mortality on dietary intake of fatty acids. International Journal of Molecular Sciences, 16(6), 12871-12890.

Parreira, T. F., Ferreira, M. M. C., Sales, H. J. S., \& de Almeida, W. B. (2002). Quantitative determination of epoxidized soybean oil using Near-Infrared spectroscopy and multivariate calibration. Applied Spectroscopy, 56(12), 1607-1614.

Pérez, J. D. E., Haagenson, D.M., Pryor, S. W., Ulven, C.A., \& Wiesenborn, D.P. (2009). Production and characterization of epoxidized canola oil. American Society of Agricultural and Biological Engineers, 52(4), 1289-1297.

Przybylski, R. (2005). Canola Oil: Physical and Chemical Properties. John Wiley \& Sons, Ltd, New Jersey.

Purbaya, M., Nor, H. M., \& Suwardin, D. (2015). Synthesis of Sunflower Oil Based Elastomer and Its Characterization by Using Spectroscopic Techniques. Macromolecular Symposia. 353, 161-167.

Sahoo, S. K., Mohanty, S., \& Nayak, S. K. (2015). Synthesis and characterization of bio-based epoxy blends from renewable resource based epoxidized soybean oil as reactive diluent. Chinese Journal of Polymer Science, 33(1), 137-152.

Salih, A. M., Ahmad, M., Ibrahim, N. A., Dahlan, K. Z. H. M, Tajau, R., Mahmood, M. H., \& Wan Yunus, W. M. Z. (2015). Synthesis of radiation curable palm oilbased epoxy acrylate: NMR and FTIR 
spectroscopic investigations. Molecules, 20, 14191-14211.

Setyaningrum, D. L., Riyanto, S., \& Rohman, A. (2013). Analysis of corn and soybean oils in red fruit oil using FTIR spectroscopy in combination with partial least square. International Food Research Journal, 20(4), 1977-1981.

Shi, L., Liu, Z., Li, J., \& Qin, Z. (2017). Analysis of Edible Vegetable Oils by Infrared Absorption Spectrometry. Advances in Engineering Research, 86, 286-289.

Sienkiewicz, A. M., \& Czub P. (2016). The unique activity of catalyst in the epoxidation of soybean oil and following reaction of epoxidized product with bisphenol A. Industrial Crops and Products, 83, 755773.
Starostina, I. V., Porozhnyuk, E. V., \& Stolyarov, D. V. (2020). The processing of kieselguhr sludge with obtaining a new end product as reserve for reducing resources consumption of vegetable oil manufacture. IOP Conference Series: Materials Science and Engineering, 791:012075.

Tavassoli-Kafrani, M. H., van de Voort F. R., \& Curtis, J. M. (2017). The use of ATRFTIR spectroscopy to measure changes in the oxirane content and iodine value of vegetable oils during epoxidation. European Journal of Lipid Science and Technology, 119(7).

Vlcek, T., \& Patrovic, Z. S. (2006). Optimization of the chemoenzymatic epoxidation of soybean oil. Journal of the American Oil Chemists' Society, 83, 247-252. 